\title{
Athlete Brand Development in Social Media: Analysis of Students' Attitudes
}

\author{
Karolina Deliautaitė, Silvija Baubonytė, Inga Staškevičiūtė-Butienė, Irena Valantinè \\ Lithuanian Sports University, Kaunas, Lithuania
}

\begin{abstract}
Background. Athlete brand image management is one of the most popular topics of discussion in sport management right now. As professional sport has become a commercialised industry segment with more athletes involved, athletes are becoming promotional faces. Most professional athletes are involved in the use of social networks. There athletes actively demonstrate their personal lives, professional accents and advertise products. It is important to understand and analyse the impact of social networks on an athlete's brand and ways to properly position themselves in social media. Using social networks, athletes are closer to fans and consumers than ever before. Based on and applying the Athlete Brand model developed by Arai (2010), this study aimed to investigate students' attitudes towards athletes' self-positioning on social networks.

Methods. The study involved 367 students (151 men and 216 women) from three Lithuanian universities. The Arai (2010) questionnaire was used for the study. Statistical analysis of the data was performed using SPSS 26.0.

Results. It has been found that athletes' sports performance is statistically significant in the development of a professional athlete's brand, it is the fundamental aspect that creates the initial status of athlete's brand. Results showed that the strongest direct causal link was found between an athlete's athletic performance and lifestyle. It was also found that very strong links, in the opinion of the respondents, were between the athletes' communication and behaviours.

Conclusions. When building an athlete's brand, it is important to pay attention to three key components: athletic performance, attractive appearance, and marketable lifestyle. These three uses of an athlete's brand can be explained by specific aspects of sports competitions or components of personal life. However, one of the most important factors in shaping a positive image of an athlete is athletic achievements.

Practical implications. This study can provide a consistent consumer approach to key aspects, focusing on consumer attention in athlete positioning. This can help the athlete and marketers develop an appropriate personal branding and positioning strategy in social media, which will then broaden the circle of fans and strengthen the opinion of loyal fans. Athlete's brand is a set of closely interrelated and fan-centred physical, functional, aesthetic, and emotional elements that sets athlete's brand apart from competitors and creates financial benefits for the athlete. The brand creates benefits not only for the athlete, but also for the market participants around him/her (consumer/fan, commercial brand), which can be called the functions of the brand.
\end{abstract}

Keywords: Athlete's image, social network, brand relationship.

\section{INTRODUCTION}

$\mathrm{T}$ The growing use of social media in the world has become one of the most important technologies of our time. Facebook, as the largest social network in the world, provides statistics on its official website, which show a trending increase in users reaching as many as 2.8 billion active users in the fourth quarter of 2020
(Tankovska, 2021). With the increasing availability of social networks in society, the benefits of social networks for athletes and sports clubs are visible. These days, a combination of social media and the digital world give a unique opportunity for athletes to create and develop their own personal brand image (Na, Kunkel, \& Doyle, 2020). Social media is 
now an extremely popular means of communication (Yadav \& Rahman, 2017) and also a powerful tool for athlete brand development (Carlson \& Donavan, 2013; Kunkel, Scott, \& Beaton, 2016). Therefore, creating a personal brand for a professional athlete becomes both important and beneficial. As professional sport becomes a commercialised segment of the industry that involves more athletes, as a result, athletes become promotional faces. Therefore, the relationship between the athlete and the business has become closer (Cobbs, Groza, \& Rich, 2016). In the professional sports industries, the concept of sports celebrity and athlete brand has been created (Arai, Ko, \& Ross, 2014).

Athlete brand is associated with a unique name, appearance, and distinctive qualities that are recognisable and distinguishes the individual from other competitors in the market (Parmentier \& Fischer, 2012; Schmidt, Shreffler, Hambrick, \& Gordon, 2018). Arai et al. (2014) define athlete brand as a public personality that associates its name, face, or other elements of the brand in the marketplace with symbolic meaning and value. Khedher (2015) associates the athlete's brand with goods or services that evolve through product development, advertising concepts, and emphasises the importance of professional athletes remaining competitive at every stage of their career for the success of their brand (O'Reilly \& Braedley, 2008). Brand retention depends on its awareness and personal characteristics (Cortsen, 2013; Hasaan, Biscaia \& Ross, 2019). Parmentier and Fischer (2012) highlight and emphasise the goal of an athlete brand - to strengthen the unique connection between the athlete and the fans. According to Cortsen (2013), an athlete brand can be influenced by positive and negative consumer mental associations with it. In this case, achievements often have a positive effect, and misconduct can have a negative effect on an athlete's image in society. Therefore, there is a great deal of pressure on an athlete's exemplary behaviour, in which case not only the achievements or achievements of the athlete as a professional athlete in the world of sports, but also personal life and activities outside the sports arena become important (Arai \& Kaplanidou, 2013). Athletes need to take care of their brand and its representation in the public space, as sports fans are often unable to distinguish the real experience from what is presented in the media (Geurin-Eagleman \& Burch, 2016; Ilicic, Baxter, \& Kulczynski 2016).
When defining athlete brand, it is important to understand its concept. Arai et al. (2013, 2014,) developed the Athlete Brand Model (MABI), which classifies the sports brand into three main categories. In this conception, there are three essential dimensional attributes in the concept of athlete brand definition: athletic performance, attractive appearance, and marketable lifestyle. These attributes are divided into 10 more subattributes (Arai et al., 2013, 2014).

Based on Arai et al. (2014), the first attribute such as athletic performance is linked to sporting activities and is further subdivided into sporting experience, competition style, sporting mastery, and rivalry. The first characteristic of athletic performance is an athlete's competence, which includes athletic achievements and abilities, e.g. victories, skills related to the athlete's sport. Schweizer \& Dietl (2015) found that athlete sports performances comprised the most important factor in enabling athletes to be identified in the target market. Athlete competition style is a specific characteristic of an athlete with their performance in competition. The competition style also indicates an athlete's specific competitive characteristics.

The second attribute - attractive appearance - is associated with an athlete's appearance and overall image. It refers to the physical characteristics of an athlete and is further subdivided into physical attractiveness, symbol, and body fitness. An attractive athlete's appearance is characterised by physical attractiveness, symbolism, and body fitness. Arai (2013) identifies this category as one of the most important aspects that characterises a brand and combines the adjacent dimensions of athletic performance and marketed lifestyle. The consumer tends to form positive stereotypes when they see a physically attractive communicator (Arai \& Ross, 2014). Besides, physically attractive communicators are better at changing beliefs and have a greater influence on consumer choices and opinion formation than unattractive communicators (Koo \& Hardin, 2008). Also Koo \& Hardin (2008) argue that aesthetic appeal is one of the motives that motivate the user to become attached to a sports team or athlete. In terms of physical attractiveness, this can be termed as athlete's physical quality and qualities that look aesthetically to viewers. Physical attractiveness is not limited to an athlete's face or physical structure, but also includes their physical expression in a specific sport (Koo \& Hardin, 2008), and distinguishes between physical and social 
attractiveness. Thus, attractiveness can be any arbitrary, exclusive, and non-descriptive feature of an athlete that can be recognised or appreciated by the public.

The third attribute is marketable lifestyle. This section describes the associations related to the off-field characteristics of the athlete. This dimension is further divided into life history, role model, relationship effort and reflects the athlete's communication with supporters, the media, and the athlete's behaviour in society (Arai et al., 2013). Perceived attributes contribute to the relationship between fans and athletes when the user makes a connection between the athlete and the brand (Kunkel, Scott, \& Beaton, 2016). In today's sports market, prominent athletes gain a certain status not only because of their excellent sports performance but also because of their distinctive lifestyle (Choi $\&$ Rifon, 2007). The dimension we examine, the lifestyle, is associated with an athlete's activities outside the field, e.g. life history, relationships, and the athlete's values. Studies have shown that one unique positive or negative episode of life can increase or decrease an athlete's value (Arai, 2013). Analysing the sub-dimension of the role model follows the ethical behaviour of the athlete, which is worth repeating by the norms and opinions set by society. This may be related to the athlete's active participation in social activities. Communication with fans, the media, and sponsors is also a crucial factor in creating the image of an athlete in the public space. Also, out-of-competition athletes' activities have become a vital complement of their performances, promoting both the athlete as a brand and the sport itself (Cortsen, 2013), as the athlete's brand nowadays is highly relevant to all possible aspects of their life, including activities during competition and personal life (Hasaan et al., 2016; Hasaan et al., 2019; Parmentier \& Fischer, 2012). Only an effective and well-formed action strategy can optimise self-positioning and benefit the athlete, and his or her associated sponsors.

\section{METHODS}

Research methods. The study used a questionnaire developed by Arai (2010), which included athletic performance, attractive appearance, and marketable lifestyle. This questionnaire is chosen to assess students' attitudes towards the professional athlete's brand and the factors that link it. The research questionnaire consisted of three parts. The first part of the questionnaire was designed to find out the social and demographic characteristics of the respondents. The second part of the questionnaire was designed to determine the general perception of respondents about the image of a professional athlete based on the model of image creation of an athlete. The third part was designed to determine respondents' attitudes to the creation of an athlete's professional image in a public space based on the athlete's image creation model. The questions in the questionnaire were divided according to the dimensions and sub-dimensions of the athlete image model developed by Arai (2010) and consisted of athletic performance (athletic expertise, competition style, sportsmanship, and rivalry), attractive appearance (physical attractiveness, symbol, and body fitness), marketable lifestyle (life story, role model, and relationship efforts). Each of the factors had several questions which had to be evaluated on a 7-point Likert scale from 1 (I totally disagree) to 7 (I totally agree).

Sample of Participants. The study involved 367 first and second cycle students at Klaipeda University, Šiauliai University, and Lithuanian Sports University. To participate in the study, the following inclusion criteria for participants were considered: (1) to be a university student, (2) study in a sports programme, and (3) use social media. The demographic characteristics of subjects are presented in Table 1.

Table 1. Demographic characteristics of subjects

\begin{tabular}{|c|c|c|c|}
\hline \multicolumn{2}{|c|}{ Demographic variables } & \multirow{2}{*}{$\begin{array}{l}N=367 \\
151\end{array}$} & \multirow{2}{*}{$\begin{array}{l}\text { Percentage } \\
41.1 \%\end{array}$} \\
\hline & Man & & \\
\hline & Woman & 216 & $58.9 \%$ \\
\hline \multirow{3}{*}{ Age } & $18-25$ & 252 & $68.7 \%$ \\
\hline & $26-35$ & 81 & $22.6 \%$ \\
\hline & $36--5$ & 32 & $8.7 \%$ \\
\hline \multirow{3}{*}{ University } & Klaipėda University & 60 & $16.3 \%$ \\
\hline & Šiauliai University & 62 & $16.9 \%$ \\
\hline & Lithuanian Sports University & 245 & $66.8 \%$ \\
\hline \multirow{3}{*}{ Activity } & Non-athletic & 54 & $14.7 \%$ \\
\hline & Professional athlete & 118 & $32.2 \%$ \\
\hline & Amateur sports & 195 & $53.1 \%$ \\
\hline
\end{tabular}


Statistical analysis. The data obtained were systematised and processed by statistical data analysis using SPSS 26.0 (Statistical Package for Social Sciences) program. The Cronbach's alpha criteria were calculated to assess the reliability of the questionnaire and showed that the internal reliability of the questionnaire was high and usable $(\alpha=.96)$. According to Hair, Black, Babin, Anderson, \& Tatham (2006), to assume that a Cronbach's alpha value is appropriate, the value of the indicator must exceed $\alpha>.70$. The Pearson's correlation coefficient was also calculated to confirm the strength of the relationship between the dimensions and sub-dimensions of the model. Chi-squared calculations were used to calculate $p$ values.

\section{RESULTS}

When choosing a significant athlete, it was observed that men $(63.6 \%)$ and women $(56.0 \%)$ mostly chose male athletes. It was found that in social networks, respondents viewed the profile or account of their chosen athlete daily, $34.9 \%$ of them were women and $25.6 \%$ men. At least once a week, the athlete's profile was viewed by $18.2 \%$ women and $12.3 \%$ men. Only $5.7 \%$ of female and $3.3 \%$ of the male athletes' accounts were reviewed 1-2 times a month on social media. The data showed that women observed and followed their favourite athletes more often in social media (58.8\%) than men (41.2\%). Respondents who were amateur and professional athletes were statistically significantly $(p<.05)$ more likely to be interested in sports and well-known athletes than non-sporting respondents.

The study first examined the relationship between the dimensions of the model (MABI). Pearson's correlation analysis confirmed a high direct relationship between sports performance and lifestyle $(p<.01)$, sports performance and appearance $(p<.01)$ and, finally, lifestyle and appearance $(p<.01)$.

The evaluation of the obtained data showed the strongest relationship between an athlete's communication and behaviour $(r=.706, p<.01)$, an athlete's communication and style $(r=.634, p<.01)$ and an athlete's communication and athletic fitness $(r=.539, p<.01)$.

Assessing the general opinion of respondents about athletic performance, the statements that scored the most were: a professional in their field (6.42 points), brave (6.38 points), knows their sport (6.27 points), has strong competitors (6.26 points), is talented (6.24 points), has important achievements (6.24 points), competing style is nice (6.23 points), it is interesting to watch the match (6.20 points). The lowest average score was seen in the statement: has a high level of skills in sport (4.24 points). Based on the obtained results, it can be stated that the professionalism and ability of the

Table 2. The correlation coefficient between sub-dimensions of athlete brand

\begin{tabular}{|c|c|c|c|c|c|c|c|c|c|c|}
\hline & 1 & 2 & 3 & 4 & 5 & 6 & 7 & 8 & 9 & 10 \\
\hline Communication & 1 & & & & & & & & & \\
\hline Athlete Behaviour & $.706^{* *}$ & 1 & & & & & & & & \\
\hline History & $.488^{* *}$ & $.384^{* *}$ & 1 & & & & & & & \\
\hline Physical attractiveness & $.370^{* *}$ & $.289^{* *}$ & $.255^{* *}$ & 1 & & & & & & \\
\hline Style & $.634^{* *}$ & $.515^{* *}$ & $.509^{* *}$ & $.515^{* *}$ & 1 & & & & & \\
\hline Sports preparation & $.539^{* *}$ & $.569^{* *}$ & $.346^{* *}$ & $.265^{* *}$ & $.466^{* *}$ & 1 & & & & \\
\hline Achievements & $.336^{* *}$ & $.517^{* *}$ & $.238^{* *}$ & $.222^{* *}$ & $.237^{* *}$ & $.490^{* *}$ & 1 & & & \\
\hline Sporting competence & $.304^{* *}$ & $.387^{* *}$ & $.185^{* *}$ & $.190^{* *}$ & $.250^{* *}$ & $.371^{* *}$ & $.605^{* *}$ & 1 & & \\
\hline Competition style & $.336^{* *}$ & $.517^{* *}$ & $.238^{* *}$ & $.222^{* *}$ & $.237^{* *}$ & $.490^{* *}$ & $.677^{* *}$ & $.605^{* *}$ & 1 & \\
\hline Competition & $.140^{* *}$ & $.193^{* *}$ & $.101 *$ & $.108^{*}$ & $.084^{*}$ & $.205^{* *}$ & $.265^{* *}$ & $.261^{* *}$ & $.288^{* *}$ & 1 \\
\hline
\end{tabular}


athlete to compete is a very important factor for the respondents. In terms of lifestyle, the majority of respondents received a positive assessment of the statement: personal life is sociable (6.23 points). Also, the majority of respondents were positive about the statements: inspires people (6.16 points), has a dramatic personal life (6.14 points). When assessing the appearance of the chosen athlete, the following statements scored the most: the style corresponds to the latest fashion trends (6.48 points), looks strong (6.22 points), and is in good physical shape (6.20 points), the athlete's style is attractive (6.16 points).

When evaluating athlete brand from a gender perspective, based on three-dimensional measurements, statistically significant statements were selected that were most significant both for women and men. The following statements were included in the athletic performance: the athlete has good sports skills $(p<.05)$, the athlete's competition is dramatic $(p<.001)$, the athlete's performance is exciting $(p<.001)$, is in good shape $(p<.001)$, the competition style is charismatic ( $p<$ $.05)$, very well understands/knows their sport ( $p<$ $.001)$, has received awards $(p<.05)$, is well-ranked $(p<.001)$, has important achievements $(p<.001)$. Assessing the athlete's lifestyle from the gender perspective, the following statistically significant statements were found: is socially responsible ( $p<$ $.001)$, has a dramatic personal life $(p<.05)$, tries to communicate with fans $(p<.05)$ and cares about fans $(p<.001)$, never uses illicit drugs $(p<.05)$, is a good example for others $(p<.05)$. Assessing the athlete's appearance in terms of gender, the following statistically significant statements were observed: is aesthetically pleasing ( $p<.001)$, has exceptional brands $(p<.001)$, looks strong $(p<$ $.001)$, the body is perfect for sports $(p<.001)$, wears attractive uniform sportswear $(p<.05)$, is beautiful $(p<.05)$, is in good physical shape $(p<.05)$, is physically attractive $(p<.001)$.

\section{DISCUSSION}

This study aimed to find out the respondents' general attitudes towards an athlete's brand. It was also important to define the athlete's brand model and to confirm the validity of the athlete's image formation model, as the athlete's image is closely related to athlete and commercial brand and this correlation as well as its formation on social media (Arai et al., 203; Evans, 2017; Geurinas \& McNary, 2020).
Arai (2010) developed and presented an athlete image model and argued in further research that it is necessary to monitor, modify, and verify the reliability of the model's measurement scale. The relationship between the dimensions and subdimensions of the model was examined during the research carried out in the final work. The data of the study showed that the connection between all dimensions was strong. The strongest association was found between the athlete's athletic performance and lifestyle, whereas in a studies by Arai (2010) and Arai \& Ross (2014), the relationships between dimensions were also strong, but the strongest association was found between the athlete's athletic performance and appearance. The results of a study by Casperio, Pfaho, and McSherry'io (2012), Vaatainen and Dickenson (2019), Na et al., (2020) showed that the lifestyle factor was very important in the context of an athlete's brand, in its development, and in building consumer loyalty. This factor, depending on the athlete's lifestyle and efforts may be relatively more controlled than athletic performance (Arai and Ross, 2014; Casper et al., 2012). The analysis of the data obtained in the study largely confirmed the model of athlete image proposed by Arai (2010). The results of the present study confirmed the theoretical foundations developed in the field of athlete image (Braunstein \& Zhang, 2005; Choi \& Rifon, 2007). In this study, it was found that the structure of a factor is a collective force in shaping the concept of an athlete's brand image in 3 dimensions and 10 sub-dimensions. To summarise, the three main components (athlete achievement, attractive appearance, and lifestyle) have been identified as important areas for athlete branding and can be further explained by specific aspects of sporting or component-specific components.

When analysing an athlete's brand, a very important accent becomes the consumer's attitude to the athlete. A study by Cortsen (2013) has found that athlete brand can be influenced by the positive and negative consumer mental associations with it. In this case, achievements often have a positive effect, and misbehaviour can have a negative effect on an athlete's image in society. Analysing the respondents' attitudes towards the chosen image of the athlete in the public space, it was observed that the respondents (regardless of gender) were more inclined to choose the representatives of the male gender. This tendency was also observed in the study of Arai (2013), during which 467 
respondents chose a male athlete - as many as $96 \%$ of respondents. In the study conducted in the final work, $63.6 \%$ chose a male athlete. The declining trend suggests that female athletes have become more visible and valued, but men remain more attractive in the context of sport. The results of the study showed that the most statistically significant statement was distinguished in the context of an athlete's athletic performance and appearance.

\section{CONCLUSIONS}

Social media shapes consumer attitudes towards the professional athlete's brand which consists of three factors: sports performance, appearance, and lifestyle; the relationship between these factors is statistically significant. The interaction between the athlete, the consumer, and the commercial brand plays an important role in the creation of a professional athlete's brand. Athlete brand is a set of closely interrelated and fan-centred physical, functional, aesthetic, and emotional elements that sets an athlete's brand apart from its competitors and creates financial benefits for the athlete. A brand creates benefits not only for the athlete but also for the market participants around him/her (consumer/ fan, commercial brand), which can be termed as brand functions. It has been established that sporting performance, a (fundamental) aspect that creates the initial status of athlete brand, is statistically significant in the development of a professional athlete's brand. The results showed that there was a direct causal relationship between an athlete's sports performance and lifestyle. The three main components (athletic achievement, attractive appearance, and lifestyle) have been identified as important areas for athlete branding and can be further explained by specific aspects of sports competitions or component-specific components. Although the interest in female athletes on social media in this study is increasing, it still remains male-dominated. Analysing the choices of men and women, we see that regardless of gender, fans are more likely to choose male athletes as a brand they want to follow. Men's and women's views on the most important characteristics, singled and essential claims of the athlete, which stimulate interest in the athlete, also did not differ, which suggests that gender is not important to followers or fans. More important is the positioning and achievements of the athlete.

\section{REFERENCES}

Arai, A. (2010). Branding Individual Athletes: Developing a Model of Athlete Brand Image (Doctoral dissertation). USA: University of Florida.

Arai, A., Ko, Y. J., \& Kaplanidou, K. (2013). Athlete brand image: Scale development and model test. European Sport Management Quarterly, 13(4), 383-403. doi: 10.1080/16184742.2013.811609

Arai, A., Ko, Y. J., \& Ross, S. (2014). Branding athletes: Exploration and conceptualization of athlete brand image. Sport Management Review, 17(2), 97-106. https://doi.org/10.1016/j.smr.2013.04.003

Braunstein, J. R., \& Zhang, J. J. (2005). Dimensions of athletic star power associated with Generation Y sports consumption. International Journal of Sports Marketing and Sponsorship. https://doi.org/10.1108/IJSMS-06-042005-B006

Carlson, B. D., \& Donavan, D. T. (2013). Human brands in sport: Athlete brand personality and identification. Journal of Sport Management, 27(3), 193-206. https://doi.org/10.1123/jsm.27.3.193

Casper, J. M., Pfal, M. E., \& McSherry, M. W. (2012). Athletics department awareness and action regarding the environment: A study of NCAA athletics department sustainability practices. Journal of Sport Management, 26, 11-29. https://doi.org/10.1123/jsm.26.1.11
Choi, S. M., \& Rifon, N. J. (2007). Who is the celebrity in advertising? Understanding dimensions of celebrity images. The Journal of Popular Culture, 40(2), 304324. https://doi.org/10.1111/j.1540-5931.2007.00380.x

Cobbs, J., Groza, M., \& Rich, G. (2016), Brand spillover effects within a sponsor portfolio: the interaction of image congruence and portfolio size. Marketing Management Journal, 25(2), 107-122.

Cortsen, K. (2013), Annika Sörenstam - a hybrid personal sports brand, Sport, Business and Management, 3(1), 37-62. https://doi.org/10.1108/20426781311316898

Evans, J. R. (2017). A strategic approach to selfbranding. Journal of Global Scholars of Marketing Science, 27(4), 270-311. https://doi.org/10.1080/21639 159.2017.1360146

Geurin, A. N., \& McNary, E. L. (2020). Athletes as ambush marketers? An examination of Rule 40 and athletes' social media use during the 2016 Rio Olympic Games. European Sport Management Quarterly, 1-18. https://doi.org/10.1080/16184742.2020.1725091

Geurin-Eagleman, A. N., \& Burch, L. M. (2016). Communicating via photographs: A gendered analysis of Olympic athletes' visual self-presentation on Instagram. Sport Management Review, 19(2), 133-145. doi. org/10.1016/j.smr.2015.03.002 
Hair, J. F., Black, W. C., Babin, B., Anderson, R. E., \& Tatham, R. L. (2006). Multivariate data analysis. (6th ed.) New Jersey: Prentice Hall

Hasaan, A., Biscaia, R., \& Ross, S. (2019). Understanding athlete brand life cycle. Sport in Society, https://doi.org/ 10.1080/17430437.2019.1624722

Hasaan, A., Kerem, K., Biscaia, R., \& Agyemang, K. J. (2016). Athlete brand construction: A perspective based on fans' perceptions. Motriz: Revista de Educação Física, 22(3), 144-159. https://doi.org/10.1590/S19806574201600030005

Ilicic, J., Baxter, S. M., \& Kulczynski, A. (2016). The impact of age on consumer attachment to celebrities and endorsed brand attachment. Journal of Brand Management, 23(3), 273-288. https://doi.org/10.1057/ bm.2016.5

Khedher, M. (2015). A brand for everyone: Guidelines for personal brand managing. Journal of Global Business Issues, 9(1).

Koo, G.Y., \& Hardin, R. (2008), Difference in the interrelationship between spectators' motives and behavioral intentions based on emotional attachment, Sports Marketing Quarterly, 17(1), 30-43.

Kunkel, T., Scott, O., \& Beaton, A. (2016). Interview with Michael Lahoud, professional soccer player: Lessons of personal athlete branding via social media. International Journal of Sport Communication, 9(4), 415-423. doi: 10.1123/IJSC.2016-0085

Na, S., Kunkel, T., \& Doyle, J. (2020). Exploring athlete brand image development on social media: The role of signalling through source credibility. European Sport Management Quarterly, 20(1), 88-108. https://doi.org/ $10.1080 / 16184742.2019 .1662465$
O'Reilly, N. J., \& Braedley, L. A. (2008). Celebrity athletes and athletic clothing design: Branding female tennis players. International Journal of Sport Management and Marketing, 3(1-2), 119-139. https://doi.org/10.1504/ IJSMM.2008.015964

Parmentier, M. A., \& Fischer, E. (2012). How athletes build their brands. International Journal of Sport Management and Marketing, 11(1-2), 106-124. doi: 10.1504/IJSMM.2012.045491

Schmidt, S.H., Shreffler, M.B., Hambrick, M.E., \& Gordon, B. S. (2018), An experimental examination of activist type and effort on brand image and purchase intentions, Sports Marketing Quarterly, 27, 31-43.

Schweizer, N. and Dietl, H.M. (2015), Brand management throughout professional athletes' careers, The IUP Journal of Brand Management, 12(4), 39-57. https://doi.org/10.2139/ssrn.2571871

Tankovska, H. (2021). Number of monthly active Facebook users worldwide as of 4th quarter 2020. Retrieved from https://www.statista.com/statistics/264810/number-ofmonthly-active-facebook-users-worldwide/

Väätäinen, M., \& Dickenson, P. (2019). (Re) examining the effects of athlete brand image (ABI) on psychological commitment: An empirical investigation using structural equation modelling (SEM) and fuzzy set qualitative comparative analysis (fsQCA). European Sport Management Quarterly, 19(2), 244-264. https://doi.org/1 $0.1080 / 16184742.2018 .1508242$

Yadav, M., \& Rahman, Z. (2017). Measuring consumer perception of social media marketing activities in e-commerce industry: Scale development \& validation. Telematics and Informatics, 34(7), 1294-1307. https:// doi.org/10.1016/j.tele.2017.06.001 